\title{
Sexual behaviour in women attending a genitourinary medicine clinic
}

\author{
B A EVANS,* R A BOND, $\dagger$ K D MACRAE $\dagger$ \\ From the *Department of Genitourinary Medicine, West London Hospital, and the $\dagger$ Charing Cross and \\ Westminster Medical School, London
}

SUMMARY In 1025 women attending a genitourinary medicine (GUM) clinic, sexual experience had started at an increasingly early age during the past 30 years, from a mode of 19 in the early 1950s to 16 in the early 1980 s. Up to the age of 40 , sexually active older women had as many recent sexual partners as younger women. Oral intercourse (fellatio) was practised by $714(70 \%)$ women, and 378 $(37 \%)$ experienced ejaculation in the mouth. Anal intercourse was practised by $200(20 \%)$ women and $90(9 \%)$ experienced ejaculation in the anorectum. The prevalence of all these practices increased with age. Women attending a Family Planning Association (FPA) clinic reported a similar prevalence of these practices, and differed from GUM clinic women only in the number of sexual partners in the preceding year. In the GUM group, black women reported significantly fewer recent sexual partners than did white women, and significantly fewer black women practised oral intercourse or permitted anal penetration. Full anal intercourse with ejaculation into the anorectum was practised at least occasionally by $9 \%(80 / 873)$ of white and $8 \%(10 / 131)$ of black women.

Despite the rising incidence and increasing importance of sexually transmitted diseases (STDs), little attention has been paid to relevant aspects of sexual behaviour of women at risk. Rotkin in California compared a group of 416 patients with cervical carcinoma with hospital controls matched for age, race, and religion.' He found a positive correlation with early coitus and multiple partners for the patients with carcinoma. These findings were confirmed by Harris et al. ${ }^{2}$ Neither of these studies nor that of Kinsey et al gave data concerning anal intercourse, ${ }^{3}$ a practice now implicated in the spread of infection with human immunodeficiency virus (HIV) in homosexual and bisexual men. ${ }^{45}$

Cornthwaite $e t$ al, however, gave a simple questionnaire to 105 female contacts of men with gonorrhoea in London and found that $18 \%$ had indulged in anal coitus and $41 \%$ in oral coitus during the preceding three months. ${ }^{6}$ Hite also reported that $10.5 \%$ of 1394 responders to her mailed questionnaire enjoyed occasional anal penetration by the penis, ${ }^{7}$ and Bolling interviewed 526 consecutive patients attending a gyn-

\footnotetext{
Address for reprints: Dr B A Evans, Department of Geniurinary Medicine, West London Hospital, Hammersmith Road, London W6 7DQ
}

Accepted for publication 10 May 1987 aecology clinic in San Antonio, Texas USA $(55 \%$ of whom were Mexican American) and found that $8 \%$ had regular pleasurable anal intercourse and $25 \%$ had tried anal intercourse at least once.

The present study looked at similar aspects of sexual behaviour in patients undergoing examination for STDs. Patients were asked about numbers of partners during the preceding year, as an index of current promiscuity, and about anal and oral intercourse, as an indication of exposure to anorectal and pharyngeal or enteric infections. Reproducibility was tested by questioning about $10 \%$ of the patients again at follow up. A small sample was also drawn from the Family Planning Association (FPA) contraceptive clinic in the same hospital to examine whether any behavioural characteristics were more common in sexually active women attending a genitourinary medicine (GUM) clinic.

\section{Patients and methods}

In February to June 1982, all women attending the department of genitourinary medicine at the West London Hospital for the first time were asked to complete a questionnaire in private while they awaited examination. The form was then filed in the clinic records. As a measure of reproducibility for this rather sensitive reported data, every tenth patient was asked 
Table 1 Numbers of sexual partners of 1025 patients attending genitourinary medicine (GUM) and 125 attending Family Planning Association (FPA) clinics

\begin{tabular}{|c|c|c|c|c|}
\hline \multirow[b]{2}{*}{ No of partners } & \multicolumn{2}{|c|}{ No $(\%)$ of patients with No of partners in previous year } & \multicolumn{2}{|c|}{ No $(\%)$ of patients with No of partners in lifetime } \\
\hline & GUM clinic $(n=1025)$ & FPA clinic $(n=125)$ & GUM clinic $(n=1025)$ & FPA clinic $(n=125)$ \\
\hline $\begin{array}{r}0 \\
1 \\
2 \\
3 \\
4 \\
5 \\
>5\end{array}$ & $\begin{array}{r}18(2) \\
424(41) \\
269(26) \\
150(15) \\
77(8) \\
30(3) \\
57(6)\end{array}$ & $\begin{array}{c}4(3) \\
74(59) \\
27(22) \\
13(10) \\
2(2) \\
2 \quad(2) \\
3 \quad(2)\end{array}$ & $\begin{array}{r}5(1) \\
91(9) \\
126(12) \\
140(14) \\
121(12) \\
72(7) \\
470(46)\end{array}$ & $\begin{array}{r}1(1) \\
17(14) \\
16(13) \\
13(10) \\
8(6) \\
9(7) \\
61(49)\end{array}$ \\
\hline
\end{tabular}

Differences between two clinic populations in partners in previous year: $\chi_{s}^{2}=20 \cdot 0 ; p=0 \cdot 001$ and partners in lifetime: $\chi_{s}^{2}=6 \cdot 9 ; p=0 \cdot 2$.

to complete the questionnaire a second time when she returned for follow up one or two weeks later. A clinical note was made of additional sexual partners, if any. Later in the study it became necessary to question every fifth patient again because many defaulted from follow up, a not unusual occurrence at metropolitan GUM clinics.

Demographic and clinical data from each patient's notes were coded, with her response to the questionnaire, on an ICL punching document. The data were analysed using the SPSS package on the University of London's Amdahl computer. Tests of significance used were Student's $t$ test, the $\chi^{2}$ test, and the Kolmogorov-Smirnov test.

After completing the GUM clinic study, we studied a small sample of patients attending a contraceptive clinic run weekly by the FPA at the same hospital. The smaller size of the sample was dictated by the size of the clinic and its weekly operation. This sample was selected because it closely resembled a GUM clinic population in terms of sexual activity and accessibility. Demographic and clinical data for these patients were completed on separate forms by the FPA clinic doctors.

\section{Results}

Of 1150 consecutive new female patients attending the clinic between 4 February and 5 June 1982, 65 were not given the questionnaire - mostly because of omissions by medical staff in the early stages of the survey. Some senior staff were also reluctant to hand out the questionnaire at all, but fortunately these doctors saw few patients. Infants, children, and patients who spoke little or no English were also excluded. A total of 1085 questionnaires were presented to patients; $42(4 \%)$ failed to answer one or (sometimes) more questions, and $18(2 \%)$ refused to answer all or part of the questions. Only the 1025 patients whose questionnaires were fully completed were included in the analysis of results.

Ages ranged from 14 to 75 (mean 25.5, median $23 \cdot 5)$, and $972(95 \%)$ were aged under 40 . Of the 1025 women, $873(85 \%)$ were white, $131(13 \%)$ black, and $21(2 \%)$ asian. Marital status was as follows: 784 $(77 \%)$ were single, $134(13 \%)$ married, $101(10 \%)$ separated or divorced, and six (1\%) widowed. Pregnancy had occurred in $418(41 \%)$, of whom $250(60 \%)$ had delivered a baby and $168(40 \%)$ had undergone either induced or spontaneous abortion. Contraception was used by $740(72 \%)$ women, of whom 525 (71\%) used oral contraception, $107(15 \%)$ used an interuterine contraceptive device (IUCD), 58 (8\%) used a cap, and $37(5 \%)$ used condoms. Of the 285 women not using contraception, $32(11 \%)$ had had a hysterectomy or were sterile.

The mean ages were 13.1 years at menarche and 17.6 years at coitarche, the modal ages were 13 years and 16 years respectively, and the medians were 13.1 years and 17.3 years respectively. Table 1 shows numbers of sexual partners, both those in the previous 12 months and the lifetime total. Only $87(9 \%)$ GUM patients had had five or more partners in the previous year, 542 patients $(53 \%)$ had had five or more partners throughout their lives.

Table 2 shows that of $200(20 \%)$ patients recorded occasional or more frequent anal penetration, $90(9 \%)$ experienced at least occasional anal intercourse with ejaculation into the rectum. Oral intercourse (fellatio) proved to be very common and was practised by 714

Table 2 Anal and oral intercourse in 1025 patients attending genitourinary medicine clinic

\begin{tabular}{lllllllll}
\hline & \multicolumn{3}{l}{ Penetration } & & & \multicolumn{2}{l}{ Ejaculation } \\
\cline { 2 - 4 } \cline { 7 - 9 } Type of intercourse & Never & Occasionally & Often & & & Never & Occasionally & Often \\
\hline Anal & $825(81)$ & $185(18)$ & $15(2)$ & & $935(91)$ & $84(8)$ & $6(1)$ \\
Oral & $311(30)$ & $564(55)$ & $150(15)$ & & $647(63)$ & $316(31)$ & $62(6)$ \\
\hline
\end{tabular}


Table 3 Altered responses in 126 patients attending genitourinary medicine clinic and questioned again

\begin{tabular}{llll}
\hline & & Nature of change \\
\cline { 3 - 4 } $\begin{array}{l}\text { Subjects of } \\
\text { questions }\end{array}$ & $\begin{array}{l}\text { No (\%) of } \\
\text { altered } \\
\text { responses }\end{array}$ & $\begin{array}{l}\text { Increase } \\
\text { (older/ } \\
\text { more/yes) }\end{array}$ & $\begin{array}{l}\text { Decrease } \\
\text { (younger/ } \\
\text { fewer/no) }\end{array}$ \\
\hline $\begin{array}{l}\text { Age at menarche } \\
\begin{array}{l}\text { Age at coitarche } \\
\text { No of partners in } \\
\text { previous year }\end{array}\end{array}$ & $27(21)$ & 15 & 12 \\
$\begin{array}{l}\text { No of partners in } \\
\text { lifetime }\end{array}$ & $26(16)$ & 7 & 13 \\
$\begin{array}{l}\text { Anal intercourse } \\
\text { Oral intercourse }\end{array}$ & $35(28)$ & 20 & 6 \\
\hline
\end{tabular}

$(70 \%)$ patients, $378(37 \%)$ of whom experienced ejaculation in the mouth.

\section{PATIENTS QUESTIONED AGAIN}

We asked 130 patients to complete the questionnaire again on reattendance at the clinic. Of these, four (3\%) provided incomplete answers, but the remaining 126 questionnaires were answered completely. The original protocol to question every tenth patient again had to be modified to every fifth patient because of the high default rate. Table 3 shows the results of questioning again. Changes in initial response were more or less equally divided between increases and decreases except for questions about numbers of sexual partners. Most patients who altered their replies to these questions recorded more partners. On the whole, however, three out of four patients provided exactly the same response in their second completion of the questionnaire as in the first.

\section{DATA ANALYSED BY AGE COHORTS}

Patients were subdivided into four age cohorts: teens, twenties, thirties, and the over forties. Table 4 shows significant decreases in the mean age at menarche from 13.7 years in the over forties to 13 years for patients in their thirties $(p=0.004)$ and from 13.3 years for patients in their twenties to 12.8 years in the teenagers $(p=0.001)$. The reverse trend between patients in

Table 4 Age at menarche in four age cohorts of women attending genitourinary medicine clinic

\begin{tabular}{|c|c|c|c|c|c|}
\hline \multirow[b]{2}{*}{ Age cohort } & \multirow{2}{*}{$\begin{array}{l}\text { No of } \\
\text { patients }\end{array}$} & \multicolumn{2}{|c|}{ Age at menarche } & \multicolumn{2}{|c|}{ Differences } \\
\hline & & Mode & Mean & 1 & $p$ \\
\hline Teens & 193 & 12 & $12 \cdot 8$ & & \\
\hline Twenties & 599 & 13 & 13. & & \\
\hline Thirties & 180 & 13 & $13 \cdot 0$ & & \\
\hline Forties plus & 53 & 14 & $13.7 \mathrm{~S}$ & & \\
\hline
\end{tabular}

Table 5 Age at coitarche in four age cohorts of women attending genitourinary medicine clinic

\begin{tabular}{|c|c|c|c|c|c|c|}
\hline \multirow[b]{2}{*}{ Age cohort } & \multirow{2}{*}{$\begin{array}{l}\text { No of } \\
\text { patients }\end{array}$} & \multicolumn{3}{|c|}{ Age at coitarche } & \multicolumn{2}{|c|}{ Differences } \\
\hline & & Range & Mode & Mean & $t$ & $p$ \\
\hline Teens & 193 & $12-19$ & 16 & 16 & & \\
\hline Twenties & 599 & $10-26$ & 17 & & 5.36 & 0.001 \\
\hline Thirties & 180 & $13-29$ & 18 & & 1.60 & 0.111 \\
\hline Forties plus & 53 & $15-27$ & 19 & $19 \cdot 5 \mathrm{~S}$ & & \\
\hline
\end{tabular}

their thirties and patients in their twenties is not easily explained. The modal age, however, fell from 14 in patients over 40, through 13 in patients in their twenties and thirties, to 12 in the teenagers.

Table 5 shows that age at coitarche fell similarly, though not significantly, between patients over 40 and those in their thirties. On the other hand, the reductions between those in their thirties and twenties and those in their twenties and teens were highly significant (both $p=0.001$ ). Of course, differences in coitarche between the teenage cohort and the other cohorts would be expected because the teenage cohort is defined by an upper limit of 19 . Nevertheless, differences could still be related to coitarche occurring at younger ages more recently.

The data were also analysed to see whether age had any bearing on the numbers of sexual partners in the previous year. Table 6 shows that patients in their thirties showed the same range of numbers of sexual partners as did patients in their twenties and teens.

Table 7 shows the incidence of anal intercourse in three age groups. Anal penetration increased significantly $(p<0.01)$ with increasing age up to 40 , but there was no significant age influence on anal intercourse taken to ejaculation. Table 8 shows that findings regarding oral intercourse showed the same increasing experience with increasing age, both for insertion of the penis and ejaculation into the mouth.

DATA ANALYSED BY RACE

Ages at menarche and coitarche were similar in women of different race, but table 9 shows that the

Table 6 Numbers of sexual partners in previous year in three age cohorts of women attending genitourinary medicine clinic

\begin{tabular}{|c|c|c|c|c|c|}
\hline \multirow{2}{*}{$\begin{array}{l}\text { Age } \\
\text { cohorts }\end{array}$} & \multicolumn{5}{|c|}{ No (\%) with following No of partners: } \\
\hline & $l$ & 2 & 3 & 4 & $\geqslant 5$ \\
\hline $\begin{array}{l}\text { Teens }(n=191) \\
\text { Twenties }(n=595) \\
\text { Thirties }(n=174)\end{array}$ & $\begin{array}{r}77(40) \\
240(40) \\
78(45)\end{array}$ & $\begin{array}{r}54(28) \\
161(27) \\
44(25)\end{array}$ & $\begin{array}{l}27(14) \\
92(16) \\
28(16)\end{array}$ & $\begin{array}{l}12(6) \\
50(8) \\
13(7)\end{array}$ & $\begin{array}{l}21(11) \\
52(9) \\
11(6)\end{array}$ \\
\hline
\end{tabular}


Table 7 Anal intercourse in three age cohorts of 972 women attending genitourinary medicine clinic

\begin{tabular}{|c|c|c|c|c|}
\hline \multirow[b]{2}{*}{ Age cohorts } & \multicolumn{2}{|c|}{ Anal penetration } & \multicolumn{2}{|c|}{ Anal ejaculation } \\
\hline & $\overline{N o}$ & Yes (\%) & No & Yes (\%) \\
\hline $\begin{array}{l}\text { Teens }(n=193) \\
\text { Twenties }(n=599) \\
\text { Thirties }(n=180)\end{array}$ & $\begin{array}{l}165 \\
486 \\
131\end{array}$ & $\begin{array}{r}28(15) \\
113(19) \\
49(27)\end{array}$ & $\begin{array}{l}180 \\
546 \\
160\end{array}$ & $\begin{array}{l}13(7) \\
53(9) \\
20(11)\end{array}$ \\
\hline
\end{tabular}

number of sexual partners in the previous year was significantly $(\mathrm{p}<0.001)$ smaller in black than in white women. Similarly, fewer black women allowed anal penetration $(p<0.01)$ but this difference did not reach significance regarding intercourse to ejaculation $(\mathrm{p}>0.5$ ) (table 10). Regarding oral intercourse, significantly fewer black women allowed either ejaculation $(p<0.001)$ or insertion of the penis into the mouth $(\mathrm{p}<0.001)$.

\section{FPA CLINIC PATIENTS}

A much smaller sample was drawn from the independently run FPA clinic, which operates in the same hospital only once a week. This part of the study was carried out one year later in February to June 1983. The FPA clinic is much smaller than the GUM clinic, but the same protocol was used except for anonymity for data from FPA records. The clinic doctors questioned 151 women about demographic and other data not contained in the questionnaire; fully completed questionnaires were provided by 125 patients and there were no refusals. Table 11 compares demographic and other clinical data for patients from the two clinics and shows a remarkable similarity between the two groups, notably regarding single status, age, and use of oral contraception. Not surprisingly, more patients from the GUM clinic did not use contraception $(25 \% v 9 \%)$ and an unusually high proportion $(33 \% v 10 \%)$ of patients from the FPA clinic used an intrauterine contraceptive device (IUCD).

Data relating to sexual behaviour also showed great

Table 8 Oral intercourse in three age cohorts of 972 women attending genitourinary medicine clinic

\begin{tabular}{lrrlllr}
\hline & \multicolumn{2}{c}{ Oral penetration } & & \multicolumn{2}{l}{ Oral ejaculation } \\
\cline { 2 - 3 } Age cohorts & No & Yes $(\%)$ & & No & Yes (\%) \\
\hline Teens $(\mathrm{n}=193)$ & 81 & $112(58)$ & & 139 & $54(28)$ \\
Twenties $(\mathrm{n}=599)$ & 158 & $441(74)$ & & 361 & $238(40)$ \\
Thirties $(\mathrm{n}=180)$ & 44 & $136(76)$ & & 105 & $75(42)$ \\
\hline
\end{tabular}

Differences between cohorts regarding penetration: $\chi_{2}^{2}=19 \cdot 53$; $\mathrm{p}<0.001$ and regarding ejaculation: $\chi_{2}^{2}=10.02 ; \mathrm{p}<0.01$.
Table 9 Numbers of sexual partners in previous year analysed by race of 987 patients attending genitourinary medicine clinic

\begin{tabular}{lrrrrrr}
\hline & \multicolumn{5}{c}{ No (\%) with following No of partners: } \\
\cline { 2 - 6 } Race & $l$ & 2 & 3 & 4 & $\geqslant 5$ \\
\hline White $(\mathrm{n}=860)$ & $336(39)$ & $234(27)$ & $136(16)$ & $72(8)$ & $82(10)$ \\
Black $(\mathrm{n}=127)$ & $77(61)$ & $30(24)$ & $12(9)$ & $5(4)$ & 3 & $(2)$ \\
\hline Differences
\end{tabular}

similarities between patients attending GUM and FPA clinics (tables 1 and 12). Most remarkable was the similarity between the total numbers of sexual partners and the numbers of patients practising anal and oral intercourse. More sexual partners in the previous year might have been predicted in patients attending the GUM clinic because of the relation between numbers of partners and STD, which was the reason for their attending.

\section{Discussion}

This study of reported data examines essentially retrospective information concerning uncorroborated events of a very personal nature that took place sometimes many years previously. The accuracy of this information may therefore be challenged as being beyond the recall of the individual. Such criticism is implicit in this type of study, in which information sought is beyond verification. To strengthen confidence in the data, we decided to present the questionnaire a second time to an arbitrary subset of the sample one or two weeks later and check for disagreement. The outcome was reassuring in two respects. Firstly, the two responses from $91(72 \%)$ of the 126 patients questioned again agreed completely. Absolute numbers of partners were altered most, and were increased by $35(28 \%)$ patients (table 3$)$. Secondly, with this exception, altered responses were evenly balanced between increases and decreases and applied equally to mundane events like age at menarche and to more sensitive matters. As the net change between the two responses was negligible, the first was used for statistical analysis in all cases.

The results show clearly that sexual activity in women born since the second world war started at an increasingly early age. Whereas coitarche occurred most often at the age of 19 during the 1940s and 1950s, age at coitarche had fallen to 16 by the late 1970s and early 1980s. It was preceded by an earlier onset of sexual maturity during the same time, however, with menstruation starting about 12 months earlier than previously. This suggests that there was a physical basis, at least in part, for the tendency for coitarche to occur at a younger age. 
Table 10 Anal and oral intercourse analysed by race of 1004 patients attending genitourinary medicine clinic

\begin{tabular}{|c|c|c|c|c|c|c|}
\hline & \multicolumn{2}{|c|}{ White $(n=873)$} & \multicolumn{2}{|c|}{ Black $(n=131)$} & \multicolumn{2}{|c|}{ Differences } \\
\hline & No & Yes $(\%)$ & No & Yes (\%) & $\chi^{2}$ & $p$ \\
\hline $\begin{array}{l}\text { Anal penetration } \\
\text { Anal ejaculation } \\
\text { Oral penetration } \\
\text { Oral ejaculation }\end{array}$ & $\begin{array}{l}689 \\
793 \\
210 \\
512\end{array}$ & $\begin{array}{r}184(21) \\
80(9) \\
663(76) \\
361(41)\end{array}$ & $\begin{array}{r}117 \\
121 \\
92 \\
120\end{array}$ & $\begin{array}{l}14(11) \\
10(8) \\
39(30) \\
11(8)\end{array}$ & $\begin{array}{r}7 \cdot 12 \\
0 \cdot 17 \\
113.29 \\
51.64\end{array}$ & $\begin{array}{l}<0.01 \\
>0.5 \\
<0.001 \\
<0.001\end{array}$ \\
\hline
\end{tabular}

Young women might have been expected to have more sexual partners than older women, but our findings did not support this (table 6). Multiple sexual partners seemed to be characteristic of individual women until the age of 40 . On the other hand, as was predictable, women attending a clinic dealing principally with STDs had more recent sexual partners than women attending the FPA clinic (table 12). By contrast, the finding that women attending the FPA clinic had as many sexual partners in their lifetimes as patients attending a GUM clinic would not have been predicted, even with marginally older women in the FPA clinic sample. As can be seen from table 11, the two groups were closely matched for race, single status, and experience of pregnancy. A bias regarding contraceptive use was anticipated, but despite this the rates for oral contraception were almost identical.

The findings regarding anal and oral intercourse confirmed previous reports. ${ }^{6-8}$ Anal penetration was reported occasionally by almost one fifth of patients in both groups, and occasional full anal intercourse with ejaculation into the rectum was reported by $9 \%$ of the GUM clinic patients and $4 \%$ of the FPA clinic patients. Less than $1 \%(6 / 1025)$ of the GUM patients, however, used this form of intercourse often. The use of the anorectum as a sexual organ increased to the age of 40 . Oral intercourse proved to be commonplace, being reported by $70 \%$ of GUM clinic patients, with

Table 11 Demographic and clinical data of patients attending genitourinary medicine (GUM) clinic compared with those attending Family Planning Association (FPA) clinic

\begin{tabular}{|c|c|c|c|}
\hline & $\begin{array}{l}\text { GUM clinic } \\
(n=l(025)\end{array}$ & $\begin{array}{l}F P A \text { clinic } \\
(n=125)\end{array}$ & Differences \\
\hline \multicolumn{4}{|l|}{ Mean (range) } \\
\hline No $(\%)$ white & $873(85)$ & $112(90)$ & $\begin{array}{l}p=0.04^{*} \\
p=0.23+\end{array}$ \\
\hline No $(\%)$ single & 784 (77) & $92(74)$ & $p=0.55 t$ \\
\hline No $(\%)$ nulligravid & $607(59)$ & $84(67)$ & $p=0.10 \dagger$ \\
\hline \multicolumn{4}{|l|}{ Contraception: } \\
\hline No $(\%)$ nil & $285(28)$ & $\left.\begin{array}{ll}11 & (9)\end{array}\right]$ & \\
\hline 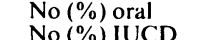 & $525(51)$ & $62(50)\}$ & $\mathrm{p}<0.0001 \dagger$ \\
\hline No $(\%)$ IUCD & $107(10)$ & $41(33)]$ & \\
\hline
\end{tabular}

penile ejaculation into the mouth being experienced by $37 \%$. Again, this practice was found to be age related up to 40 .

Black women formed $13 \%(127 / 1025)$ of the GUM clinic sample and differed significantly from the white majority in some respects. The black women were significantly less promiscuous in terms of partners during the preceding 12 months $(\mathrm{p}<0.001)$. Fellatio was also much less common in this group $(p<0.001)$, as was anal penetration by the penis ( $\mathrm{p} 0 \cdot 01)$. The proportion using the anorectum occasionally for ejaculation did not differ significantly between the two groups, being $9 \%$ in white and $8 \%$ in black women.

Information concerning the role of the mouth and anus in sexual intercourse was originally sought in connection with the transfer of potential genital pathogens. The subsequent emergence of HIV infection and the acquired immune deficiency syndrome (AIDS) has placed new importance on routes of transmission because of the incurability of HIV infection and the devastating mortality from AIDS. Transmission of HIV has been strongly associated with receiving semen in the rectum, a common practice among homosexual men. ${ }^{45}$ Anal intercourse with a bisexual man may therefore place a woman at equal risk of infection. The results of this study add further weight to previous reports that nearly one fifth of sexually active women practise anal intercourse, which

Table 12 Sexual behaviour of patients attending genitourinary medicine (GUM) clinic compared with that of patients attending Family Planning Association (FPA) clinic

\begin{tabular}{|c|c|c|c|}
\hline & $\begin{array}{l}\text { GUM } \\
\text { clinic } \\
(n=1025)\end{array}$ & $\begin{array}{l}F P A \\
\text { clinic } \\
(n=125)\end{array}$ & Differences \\
\hline $\begin{array}{l}\text { Mean age at menarche } \\
\text { (years) } \\
\text { Mean age at coitarche }\end{array}$ & 13 & 13 & $p=0.15^{*}$ \\
\hline $\begin{array}{l}\text { (years) } \\
\text { No }(\%)>1 \text { partner previous }\end{array}$ & 18 & 18 & $p=0.28^{*}$ \\
\hline year & $583(57)$ & $47(38)$ & $p=0.001^{*}$ \\
\hline No $(\%)>5$ lifetime partners & $470(46)$ & $60(49)$ & $p=0.88^{*}$ \\
\hline No $(\%)$ anal penetration & $200(20)$ & $22(18)$ & $p=0.70+$ \\
\hline No $(\%)$ anal ejaculation & 90 (9) & $5(4)$ & $p=0.10 \dagger$ \\
\hline No $(\%)$ oral penetration & $714(70)$ & $93(74)$ & $p=0.32+$ \\
\hline No $(\%)$ oral ejaculation & $378(37)$ & $56(45)$ & $\mathrm{p}=0.10 \dagger$ \\
\hline
\end{tabular}


could prove to be the most efficient route of transfer of HIV infection to the heterosexual community.

We thank Dr Jennie Lebus and her colleagues, Drs Bannerjee and Mitra, for their invaluable help in the FPA clinic part of the study.

\section{References}

1 Rotkin ID. Sexual characteristics of a cervical cancer population. Am J Public Health 1967;57:815-29.

2 Harris RWC, Brinton LA, Cowdell RH, et al. Characteristics of women with dysplasia or carcinoma in situ of the cervix uteri. $\mathrm{Br}$ $J$ Cancer 1980;42:359-69.
3 Kinsey AC, Pomeroy WB, Martin CE, Gebhard PH. Sexual hehaviour in the human female. London: WB Saunders, 1953:842 pp.

4 Goedert JJ, Sarngadharan MG, Biggar RJ, et al. Determinants of retrovirus (HTLV-III) antibody and immunodeficiency conditions in homosexual men. Lancet 1984;ii:711-6.

5 Evans BA, Dawson SG, McLean KA, et al. Sexual lifestyle and clinical findings related to HTLV III/LAV status in homosexual men. Genitourin Med 1986;62:384-9.

6 Cornthwaite SA, Savage WD, Willcox RR. Oral and rectal coitus amongst female gonorrhoea contacts in London. Br J Clin Pract 1974;23:305-6.

7 Hite S. The Hite report. London: Talmy Franklin Ltd, 1977:438 $\mathrm{pp}$.

8 Bolling DR. Prevalence, goals and complications of heterosexual anal intercourse in a gynecologic population. $J$ Reprod Med 1977;19:120-4. 